\title{
Influência da Energia de Soldagem na Microestrutura e na Microdureza de Revestimentos de Aço Inoxidável Duplex
}

\section{(Influence of the Heat Input on the Microstructure and Microhardness of Weld Overlay of Duplex Stainless Steel)}

\author{
Everton Barbosa Nunes ${ }^{1}$, Higor Jonas Batista ${ }^{1}$, Alexandre Sousa Barreto ${ }^{2}$. Jéssyca da Silva Marques ${ }^{2}$, Marcelo Ferreira Motta $^{1}$ \\ ${ }^{1}$ Universidade FederaI do Ceará, Departamento de Engenharia Metalúrgica e de Materiais/Laboratório de Engenharia de \\ Soldagem, Fortaleza, Ceará,nunesbar@ibest.com.br \\ ${ }^{2}$ Universidade FederaI do Ceará, Departamento de Engenharia Mecânica/ Laboratório de Engenharia de Soldagem, Fortaleza, \\ Ceará
}

\section{Resumo}

Aços inoxidáveis duplex (AID) são caracterizados por apresentar interessante boas propriedades mecânicas e resistência à corrosão, possuindo um vasto campo de aplicação na indústria química e petroquímica. Geralmente, os reparos dos equipamentos ou estruturas são realizados por soldagem, sendo importante a seleção de parâmetros. É de suma importância a obtenção do teor adequado de ferrita no metal de solda, sendo que a variação da energia de soldagem pode influenciar de forma direta no percentual de ferrita. Logo, o objetivo deste trabalho é avaliar a influência da variação da energia de soldagem na microestrutura e na microdureza do metal de solda do AID. Foram realizadas soldagens de revestimento com sobreposição de duas camadas sobre o aço estrutural ASTM A516 Gr.60, utilizando eletrodo revestido AWS E2209-17. Três níveis de energia (15, 20 e $24 \mathrm{~kJ} / \mathrm{cm})$ foram empregados, variando-se a corrente e a velocidade de soldagem. Foi verificado que para os níveis de energia empregados não houve diferença significativa no percentual de ferrita, porém o primeiro cordão depositado apresentou maior teor de austenita em relação aos demais cordões. De forma geral, foi verificado que o primeiro cordão depositado obteve níveis maiores de microdureza. Todas as condições apresentaram microdurezas abaixo do valor crítico.

Palavras-chave: Duplex; Microestrutura; Revestimento; Microdureza.

Abstract: Duplex stainless steels (DSS) are characterized by the presentation of an interesting combination of good mechanical properties and corrosion resistance, having a wide application in chemical and petrochemical industry. Generally, the manufacture and repair of any industrial equipment involve welding operations, even though it is very important to evaluate the influence of welding parameters. It is very important to obtain appropriate ferrite content in the weld metal, so that the variation of heat input can influence on the ferrite content directly. Therefore, the aim this work is to evaluate the influence of the heat input on the microstructure and the microhardness of the weld metal of the DSS. The weld overlay were performed with deposition of two layers on the structural steel ASTM A516 Gr.60, using as filler metal the AWS E2209-17 coated electrode. Three energy levels (15, 20 and $24 \mathrm{~kJ} / \mathrm{cm})$ were used, varying the welding current and speed. It was verified that for energy levels used didn't have significant difference on the ferrite content, but the first bead deposited had a higher austenite content in relation to other beads. All conditions got microhardness below the critical value.

Key-words: Duplex; Microstructure; Weld overlay; Microhardness.

\section{Introdução}

Os aços inoxidáveis duplex (AID) surgiram na década de 30 na França com o objetivo de reduzir os problemas de corrosão intergranular dos aços inoxidáveis austeníticos e, por isso, adquiriram importância comercial. Desde então, estas ligas têm sofrido inúmeras modificações, que vão desde a sua composição química até as tecnologias usadas na sua produção [1]. Uma grande vantagem da utilização dos AID é que a combinação de elementos como: cromo, molibdênio e nitrogênio conferem uma

(Recebido em 29/02/2012; Texto final em 02/03/2012).

Artigo originalmente publicado no CONSOLDA 2011 boa estabilidade química em ambientes salinos como a água do mar. Esta estabilidade só era obtida antigamente (décadas de 70 e 80) devido à utilização de materiais com altas concentrações de cobre, como por exemplo, os bronzes e materiais com altas concentrações de níquel, como os Hastelloys, os Inconéis e os Monéis [2]. No entanto, as ligas de níquel possuem elevado custo e menor resistência mecânica em relação aos aços inoxidáveis duplex, reduzindo a continuidade de uso destes materiais em grande escala.

Os AID modernos possuem uma excelente resistência à corrosão e boas propriedades mecânicas, crescendo a utilização destes materiais no Brasil a partir da década de 90, sendo que um dos mais conhecidos comercialmente é o aço inoxidável duplex UNS S31803. Esta combinação de propriedades tem popularizado o seu uso em ambientes altamente agressivos 
$[3,4]$. A combinação entre os elevados valores de alongamento da austenita com o elevado limite de escoamento da ferrita nos aços inoxidáveis duplex formam um conjunto de notáveis propriedades mecânicas, chegando a alongamento mínimo de $25 \%$ e dureza de $260 \mathrm{HV}$ [1]. O percentual de ferrita aumenta o nível de microdureza para diferenças significativas na relação austenita/ferrita, sendo a ferrita uma microestrutura mais dura e a austenita mais macia e dúctil $[5,6,7]$.

Uma grande parcela das aplicações industriais dos AID está nos setores químico, petroquímico e de papel e celulose, geralmente em equipamentos cuja fabricação envolve operações de soldagem (vasos de pressão, torres de dessulfuração, estruturas de plataformas, árvores de natal, risers, hard pipes, clads, tubulações de água produzida e injetada, trocadores de calor). Nessas aplicações citadas, seja na fabricação ou na manutenção dos equipamentos ou componentes, a soldagem é utilizada. Se não for executada com os devidos cuidados, as vantagens dos AID sobre os aços inoxidáveis tradicionais podem ser perdidas [3].

Em relação à resistência à corrosão, os AID possuem resistência em muitos ambientes, como: ácido sulfúrico, ácido hidroclorídrico ou ácido nítrico [8]. Por outro lado, podem ser mais suscetíveis à corrosão localizada, como pites e frestas [9]. $\mathrm{O}$ que caracteriza a resistência à corrosão por pite é a capacidade que o metal tem de se passivar, ou seja, formar um filme contínuo e aderente de óxidos capaz de impedir a penetração de oxigênio no metal. A corrosão por pite é caracterizada por ataque extremamente localizado, inicia-se pela quebra da película passiva em regiões onde esta apresenta defeitos como inclusões, discordâncias, contornos de grão ou interfaces. Os elementos de liga que ditam o comportamento do aço inoxidável na resistência à corrosão por pites em relação à formação da camada passivadora são Cr, Mo e N [10].

$\mathrm{O}$ índice equivalente de resistência ao pite (PRE) é em torno de 35 para o aço inoxidável duplex UNS S31803, de modo que quanto maior este valor, maior a resistência à corrosão por pites [11]. A presença de pites, além de provocar vazamentos em tanques, tubulações e recipientes, também pode levar a outras causas de falha como corrosão sob tensão, fragilização por hidrogênio, ou fadiga associada à corrosão. Os pites podem iniciar nas interfaces dos grãos austeníticos e ferríticos, pela presença de sulfeto de manganês na ferrita ou pelos baixos teores de cromo e molibdênio na austenita, comparando com a ferrita, além de inclusões, contornos de grão [12]. É um caso extremo de deterioração, onde áreas muito pequenas da superfície metálica são atacadas enquanto o restante da superfície permanece inalterado. Os pites são pontos de concentração de tensão, podendo servir de início para trincas. Podem também diminuir a resistência total ou penetrar no material completamente de modo a causar a fuga de gases ou líquidos contidos. São bastante perigosos, pois podem apresentar um diâmetro pequeno na superfície e uma profundidade difícil de ser determinada.

Logo, é primordial a obtenção do balanço microestrutural de $50 \%$ de austenita e $50 \%$ de ferrita para aliar boas propriedades mecânicas e resistência à corrosão [13]. No entanto, os estudos com soldagens multipasse têm sido superficiais, indicando uma grande motivação para realizações de trabalhos na área. Foi verificada que a liga SAF 2205 (UNS 31803) na condição recozida e soldada, a melhor combinação de resistência mecânica, tenacidade e resistência à corrosão podem ser encontradas se a fração volumétrica de ferrita estiver entre $35 \%$ e $65 \%$ [14].

Além da busca de uma energia de soldagem ótima, deve-se ainda considerar o fato de que, na soldagem multipasse, a junta é submetida a vários ciclos térmicos. Isto significa que a região soldada passa por aquecimentos e resfriamentos consecutivos, comumente pouco controlados. Tais variações de temperatura podem modificar a microestrutura original, alterar o balanço das fases e, consequentemente, afetar o desempenho da junta, modificando suas propriedades. $\mathrm{O}$ reaquecimento repetido da Zona Fundida (ZF) e da Zona Afetada pelo Calor (ZAC) pode levar à precipitação de austenita secundária e fases intermetálicas $[3,15]$.

Isto posto, esse trabalho propõe a realização de um estudo que avalie a influência da energia de soldagem no balanceamento das fases presentes, na microestrutura e na microdureza do metal de solda do aço inoxidável duplex, em soldagens multipasse.

\section{Materiais e Métodos}

Foram utilizadas chapas do ASTM A516 Gr. 60 (150x100x13 $\mathrm{mm}$ ), soldadas com eletrodo revestido AWS E2209-17, de 4,0 mm de diâmetro para deposição do revestimento em duas camadas, ocorrendo sobreposição entre passes de 30 a 50\%. A temperatura de interpasse foi mantida em aproximadamente $135^{\circ} \mathrm{C}$, sendo o controle realizado por termopar tipo K. Neste trabalho não foi realizado preaquecimento ou pós-aquecimento, pois não são recomendados nas soldagens dos AID [16]. No entanto, o controle da energia e da temperatura de interpasse durante a soldagem é requerido para a correta razão $\alpha / \gamma$ nas soldas dos AID. A temperatura de interpasse não deve exceder $250^{\circ} \mathrm{C}$, sendo que na prática esta temperatura pode ainda ser considerada alta, muitas vezes utilizando-se temperaturas abaixo de $150^{\circ} \mathrm{C}$ [17]. A composição química dos materiais utilizados é mostrada na Tabela 1.

A soldagem foi realizada conforme o esquema da Figura 1, com o auxilio de uma fonte multiprocesso e de um sistema de aquisição de sinais de corrente e tensão, a uma frequência de $9600 \mathrm{MHz}$. As energias de soldagem empregadas foram

Tabela 1. Composição química do metal base e do metal de adição.

\begin{tabular}{c|c|c|c|c|c|c|c|c|c|c}
\hline \multirow{2}{*}{ Material } & \multicolumn{10}{c}{ Composição Química (\%) } \\
\cline { 2 - 12 } & $\mathbf{C}$ & $\mathbf{M n}$ & $\mathbf{P}$ & $\mathbf{S}$ & $\mathbf{S i}$ & $\mathbf{C r}$ & $\mathbf{N i}$ & $\mathbf{A l}$ & Mo & $\mathbf{N}$ \\
\hline Metal base & 0,18 & $\mathrm{O}, 99$ & 0,023 & 0,008 & 0,20 & 0,004 & - & 0,041 & - & - \\
\hline Metal de adição & 0,03 & 0,8 & 0,03 & 0,025 & 0,9 & 23 & 9 & - & 3,0 & 0,15 \\
\hline
\end{tabular}


variadas de forma a permanecer na faixa de 5 a $25 \mathrm{~kJ} / \mathrm{cm}$ que é recomendada pela literatura, de modo a evitar precipitações de fases que poderiam comprometer de forma significante as propriedades mecânicas e resistência à corrosão [3]. Na Tabela 2 são mostrados os parâmetros de soldagem utilizados.

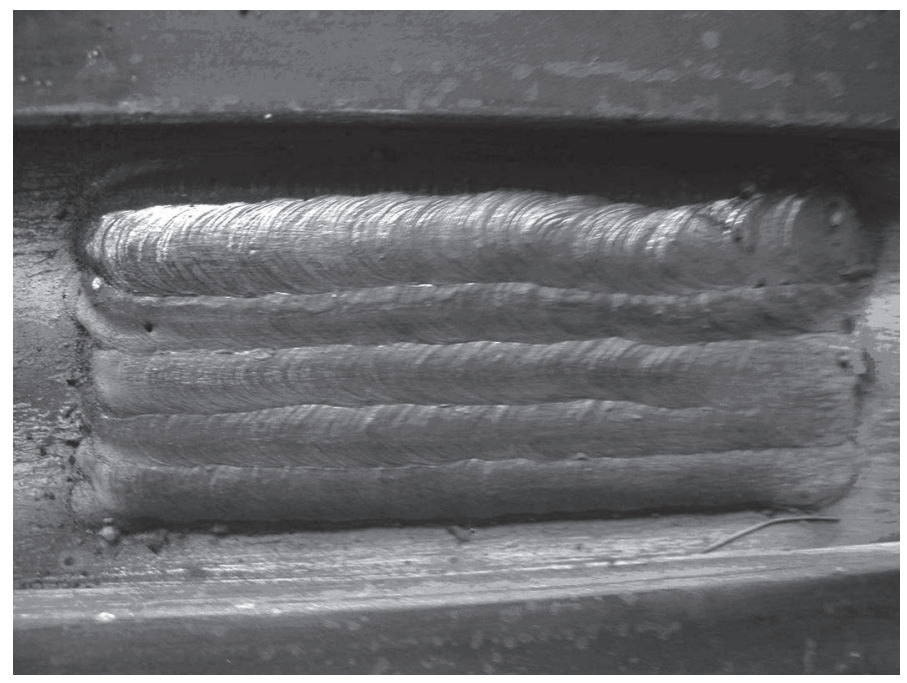

Figura 1. Esquema da sequência dos passes na soldagem multipasse.

Tabela 2. Parâmetros de soldagem por eletrodo revestido.

\begin{tabular}{c|c|c|c}
\hline Corpos de Prova & $\begin{array}{c}\mathbf{E} \\
(\mathbf{k J} / \mathbf{c m})\end{array}$ & $\begin{array}{c}\mathbf{I} \\
\text { (A) }\end{array}$ & $\begin{array}{c}\mathbf{V s} \\
\text { (cm/min) }\end{array}$ \\
\hline $\mathrm{C} 1$ & 15 & 100 & 10 \\
\hline $\mathrm{C} 2$ & 20 & 135 & 10 \\
\hline $\mathrm{C} 3$ & 24 & 160 & 10 \\
\hline $\mathrm{C} 4$ & 15 & 135 & 13 \\
\hline $\mathrm{C} 5$ & 24 & 135 & 8,0 \\
\hline
\end{tabular}

Obs.: As soldagens foram realizadas com tensão média de $31 \mathrm{~V}$ e considerando $\eta=0,8$.

Posteriormente, foram retiradas amostras com cortes na direção longitudinal, de modo a analisar o primeiro e último cordão soldado da segunda camada depositada. As amostras foram lixadas até granulometria de 600 mesh para posterior quantificação do percentual de ferrita no metal de solda. Foram realizadas 50 medições em cada cordão de solda utilizando ferritoscópio. Posteriormente, foi realizada preparação metalográfica utilizando polimento com pasta de diamante de $3 \mu \mathrm{m}$ e $1 \mu \mathrm{m}$ para caracterização do metal de solda. Para a revelação da ferrita e austenita no metal de solda foi realizado ataque eletrolítico com solução de $40 \%$ vol de $\mathrm{HNO}_{3}$ em água destilada aplicando tensão de $1,0 \mathrm{~V}$ durante $3 \mathrm{~min}$. Para verificação de austenita secundária foi realizado mesmo ataque com tensão entre 0,7 e 1,0 V durante $2 \mathrm{~min}$. Para verificação da presença de fase sigma foi realizado um ataque eletrolítico com $20 \%$ de $\mathrm{NaOH}$ com tensão de $2,0 \mathrm{~V}$ durante $10 \mathrm{~s}$. Para o registro das fotos, foi utilizado um microscópio óptico para análise microestrutural. Em relação à microdureza, foram realizadas 20 impressões ao longo de cada cordão de solda, de modo que foi utilizada carga de $100 \mathrm{~g}$ durante $15 \mathrm{~s}$. Vale salientar que para os aços inoxidáveis duplex o nível de microdureza aceitável é de até $310 \mathrm{HV}$, de modo a minimizar os problemas inerentes à propagação de trincas [17].

\section{Resultados e Discussão}

\subsection{Quantificação de Ferrita}

Foi verificado que o primeiro cordão soldado obteve menores percentuais de ferrita em relação ao último cordão soldado (Figura 2), sendo observado para todas as condições soldadas.

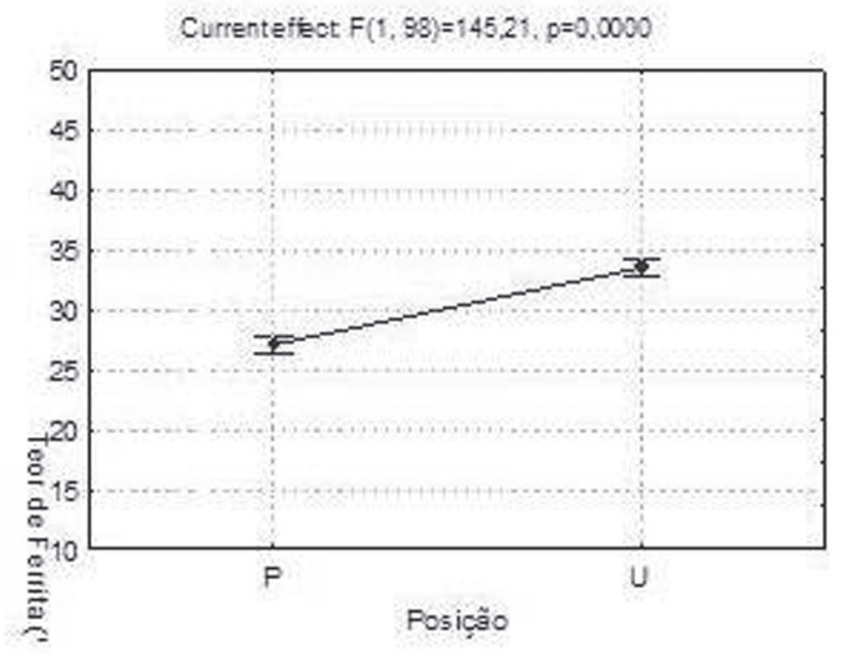

Figura 2. Teor de ferrita no metal de solda da condição $\mathrm{C} 4(\mathrm{E}=$ $15 \mathrm{~kJ} / \mathrm{cm}, \mathrm{I}=135 \mathrm{~A}$ e $\mathrm{Vs}=13 \mathrm{~cm} / \mathrm{min}$ ). P: primeiro cordão de solda; U: último cordão de solda.

É importante o percentual de ferrita no metal de solda estar na faixa de 35 a $65 \%$ [14], de modo a aliar boas propriedades mecânicas e boa resistência à corrosão.Teores excessivamente altos de ferrita causam fragilidade, maior nível de dureza enquanto ausência dessa fase causa perda de resistência à fissuração por corrosão sob tensão. $O$ primeiro cordão de solda sofre influência do ciclo térmico dos passes laterais subsequentes, ocorrendo reaquecimento, promovendo uma maior formação da fase austenítica. $O$ último cordão de solda não sofre influência de passes subsequentes, sendo que a fração de fase ferrítica é maior em comparação com o primeiro cordão depositado. Este comportamento também foi observados em outros trabalhos que realizaram soldagem multipasse $[18,19]$

Na Figura 3 é mostrado efeito da variação da energia de soldagem pela alteração da corrente de soldagem em relação ao percentual de ferrita, de modo que não foi verificada influência significativa no percentual de ferrita para os níveis de energias selecionados, tanto no primeiro ou no último cordão soldado. 


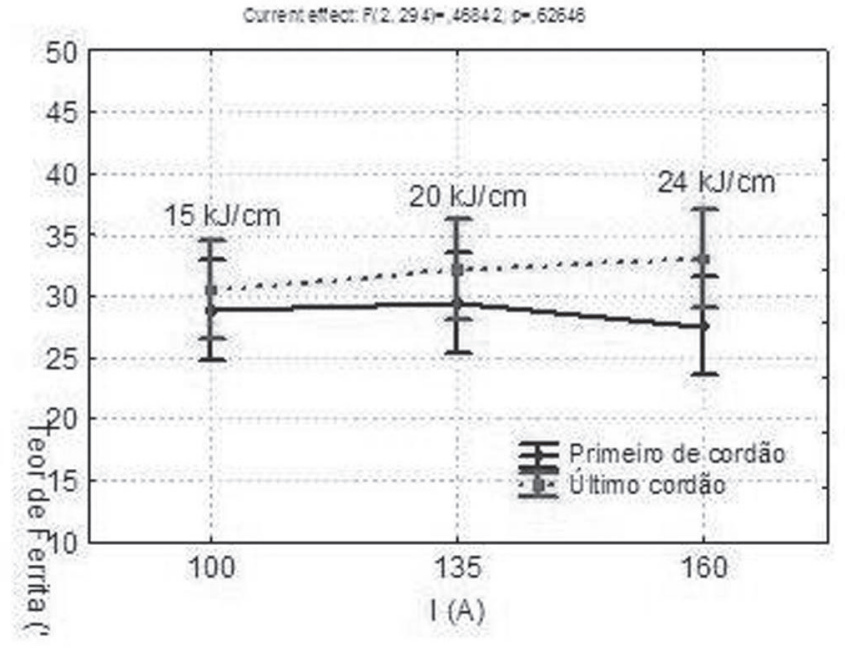

Figura 3. Efeito da corrente de soldagem no teor de ferrita no metal de solda para $\mathrm{V}_{\mathrm{s}}=10 \mathrm{~cm} / \mathrm{min}$.

Na Figura 4 é mostrado o efeito do aumento da energia de soldagem pela redução da velocidade de soldagem no teor de ferrita no metal de solda. Não foram observadas diferenças significativas no percentual de ferrita para os níveis de energias empregados no trabalho. Estes resultados são importantes, pois pode-se variar a energia de soldagem para reduzir a zona afetada pelo calor, diluição, alterar geometria do cordão de solda, aumentar produtividade, sem modificar de forma significativa $o$ teor de ferrita no metal de solda

\subsection{Microestrutura}

Durante o aquecimento, a transformação da austenita para ferrita ocorre geralmente por difusão dos elementos de liga intersticiais e substitucionais com temperaturas superiores a $1300{ }^{\circ} \mathrm{C}$. Destes elementos de liga, a difusão do nitrogênio

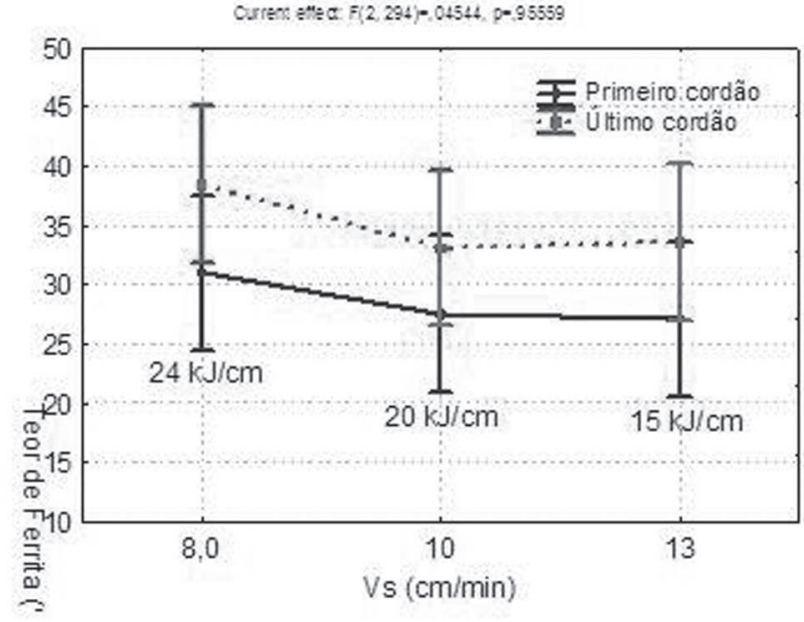

Figura 4. Efeito da velocidade de soldagem no teor de ferrita no metal de solda para $\mathrm{I}=135 \mathrm{~A}$.

controla esta transformação no aquecimento [20]. Esta difusão é afetada pelo ciclo térmico e pela partição dos elementos de liga entre os grãos ferríticos e austeníticos. Na solidificação, três diferentes morfologias básicas de austenita foram observadas no metal de solda: alotriomórfica, Widmanstätten e intragranular. A austenita alotriomórfica, que é formada a altas temperaturas, nucleia heterogeneamente nos contornos de grão da ferrita durante o resfriamento, sendo formada possivelmente por um mecanismo de transformação difusional. Depois da austenita alotriomórfica formada, a morfologia Widmanstätten nucleia nos contornos de grão da ferrita ou da austenita alotrimórfica pré-existente e cresce ao longo de planos específicos da matriz como placas paralelas [21].

Alguns trabalhos verificaram que a adição de nitrogênio e soldagens realizadas em energias mais elevadas proporcionaram uma maior formação de Widmanstätten de placas laterais, pois o tempo de permanência a altas temperaturas é maior, de modo
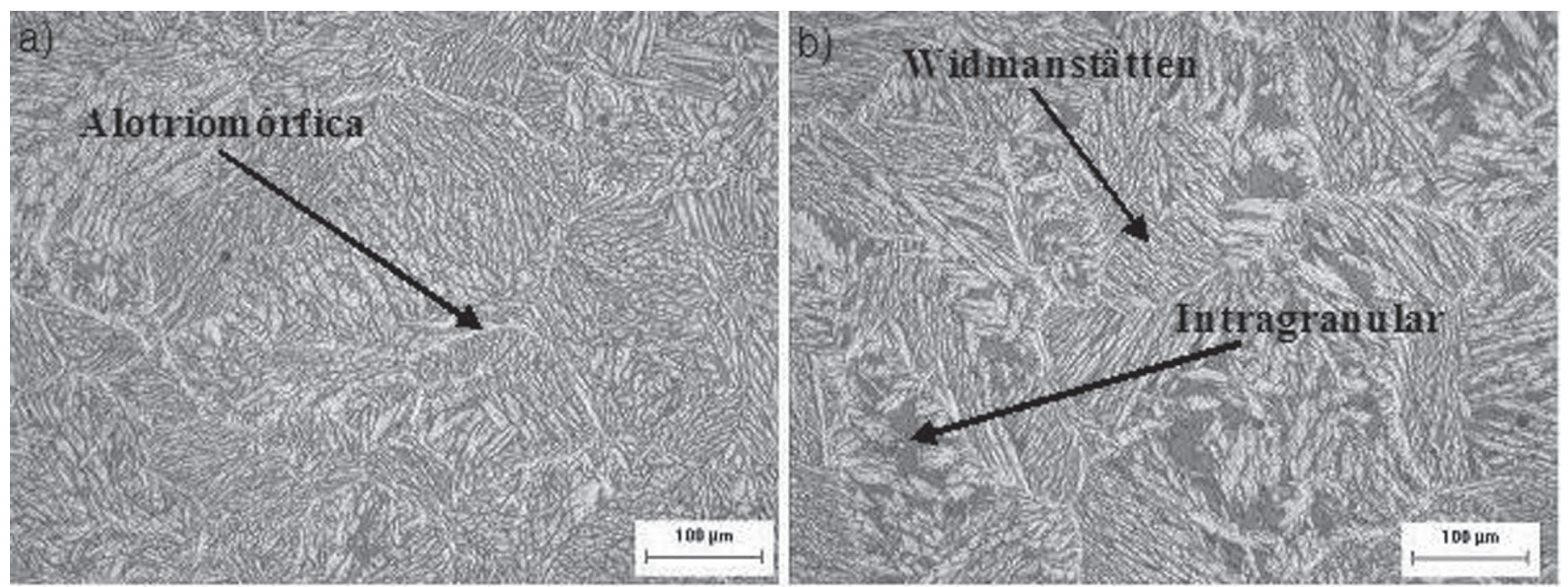

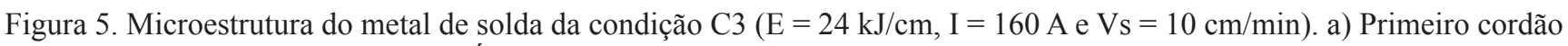
depositado; b) Último cordão depositado. Ataque com $\mathrm{HNO}_{3}$, aumento de 200x. 


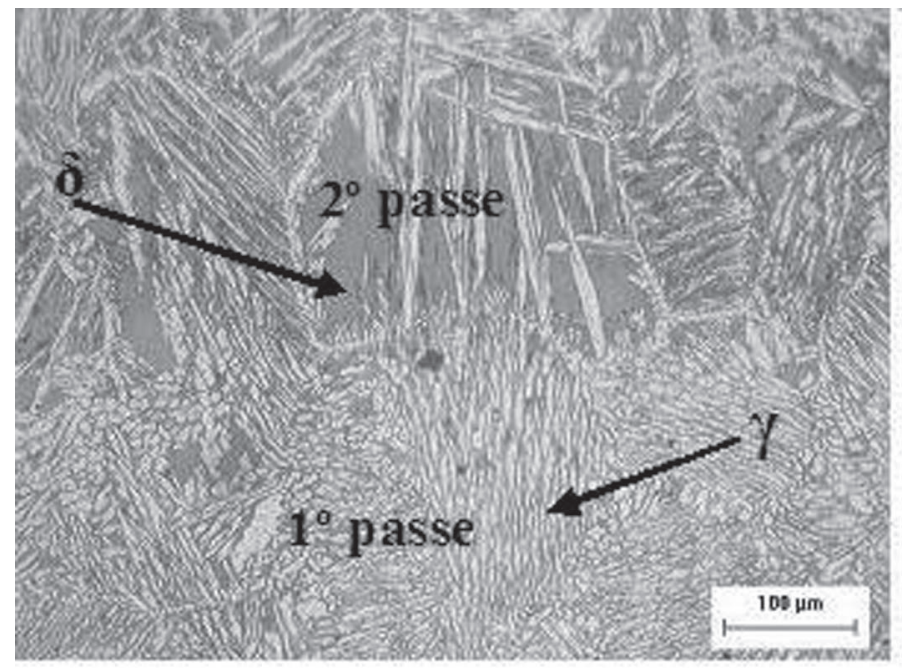

Figura 6. Microestrutura do metal de solda da condição C5 (E $=24 \mathrm{~kJ} / \mathrm{cm}, \mathrm{I}=135 \mathrm{~A}$ e $\mathrm{Vs}=8,0 \mathrm{~cm} / \mathrm{min})$. Ataque com $\mathrm{HNO}_{3}$, aumento de $200 x$.

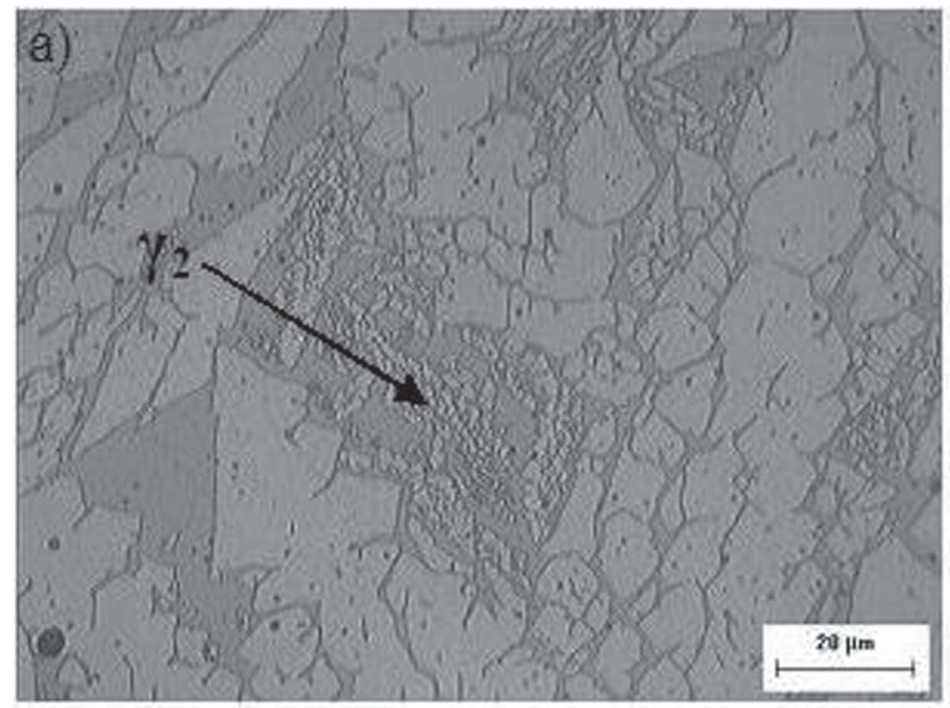

observado pela quantificação realizada pelo ferritoscópio. Quanto à morfologia da austenita, diferentes morfologias de austenita foram observadas: intragranular, alotriomórfica e Widmanstätten. Outra abordagem a ser realizada é a presença de austenita secundária que pode afetar diretamente as propriedades mecânicas e resistência à corrosão $[1,3]$.

É observada uma grande heterogeneidade da microestrutura ao longo dos passes laterais no metal de solda, ou seja, em uma mesma micrografia são encontradas regiões com elevados teores de austenita e outras regiões com baixos teores, bem como diferentes morfologias de austenita (Figura 6).

Em relação à precipitação de austenita secundária $\left(\gamma_{2}\right)$, nas condições em que houve variação da energia pela alteração da corrente de soldagem, as amostras soldadas com corrente de 100 A (C1) e 135 A (C2) apresentaram maior presença de austenita secundária (Figura 7) em relação às soldadas na condição C3 (165 A), sendo que na condição de maior energia não foi observada a presença de austenita secundária. Vale salientar que no primeiro cordão soldado, verificou-se a presença de $\gamma_{2}$, o que não foi observado no último cordão, válido para todas as condições soldadas.

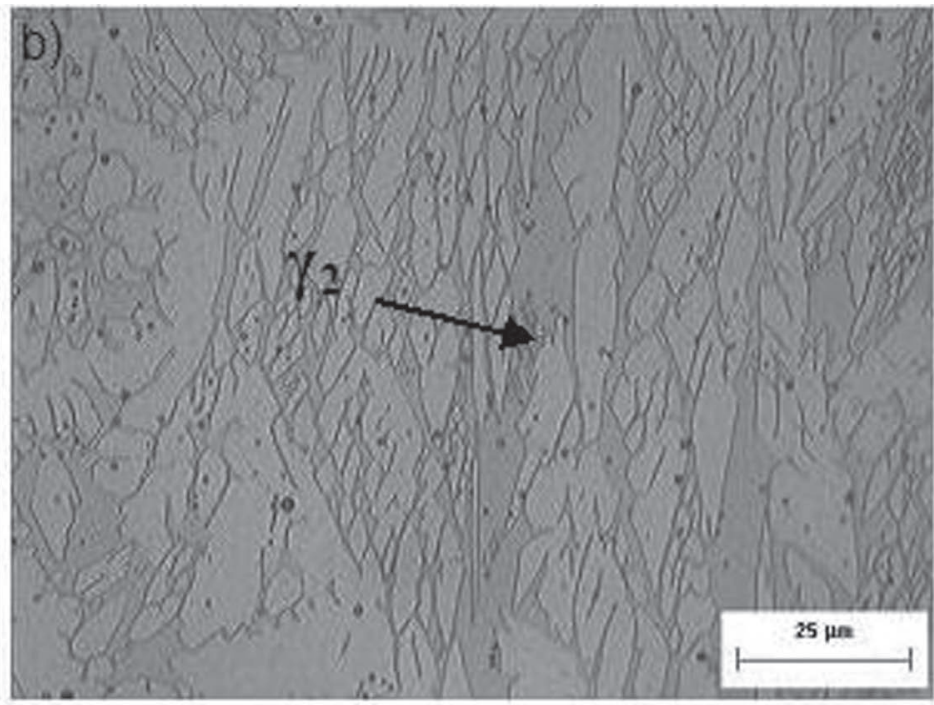

Figura 7. Microestrutura do metal de solda da condição. a)C1P $(\mathrm{E}=15 \mathrm{~kJ} / \mathrm{cm}, \mathrm{I}=100 \mathrm{~A}$ e Vs $=10 \mathrm{~cm} / \mathrm{min}) ; \mathrm{b}) \mathrm{C} 2 \mathrm{P}(\mathrm{E}=20 \mathrm{~kJ} / \mathrm{cm}, \mathrm{I}=$ $135 \mathrm{~A}, \mathrm{Vs}=10 \mathrm{~cm} / \mathrm{min})$. Ataque com $\mathrm{HNO}_{3}$, aumento de $1000 \mathrm{x}$.

que a adição de nitrogênio facilita a formação de morfologia Widmanstätten [22,23]. Porém, outros pesquisadores verificaram que maiores taxas de resfriamento proporcionaram maior formação de Widmanstätten, apenas pela alteração da energia de soldagem [24,25]. Logo, dependendo das energias empregadas, composição química e tamanho de grão, podem surgir comportamentos diferentes em termos de morfologia presente. Na literatura também foi reportada a nucleação de austenita intragranular nos grãos de ferrita. Estas são precipitadas a temperaturas mais baixas devido à supersaturação da matriz ferrítica, como foi verificado em outro trabalho [26].

Na Figura 5 é mostrado, de forma qualitativa, que o primeiro cordão depositado apresenta maior quantidade de austenita em relação ao último cordão soldado devido à sobreposição de passes subseqüentes, estando de acordo com o que foi
Nos AID, durante o resfriamento, parte da fase ferrítica se transforma em austenita primária $\left(\gamma_{1}\right)$. Caso este resfriamento seja muito rápido, a formação de $\gamma_{1}$ pode ser prejudicada, obtendo-se uma microestrutura metaestável com elevados teores de ferrita. Desta forma, durante o reaquecimento, seja por um tratamento isotérmico ou por reaquecimento devido ao processo de soldagem, a austenita secundária $\left(\gamma_{2}\right)$ precipita a partir da ferrita ou da austenita primária [3]. Segundo a literatura, os teores de $\mathrm{Cr}$, Mo e $\mathrm{N}$ da $\gamma_{2}$ formada no metal de solda de um AID são menores que os da austenita previamente existente na microestrutura [27,28].

Em relação à precipitação de austenita secundária $\left(\gamma_{2}\right)$, nas condições em que houve a variação da energia pela alteração da velocidade de soldagem, a condição soldada com menor 

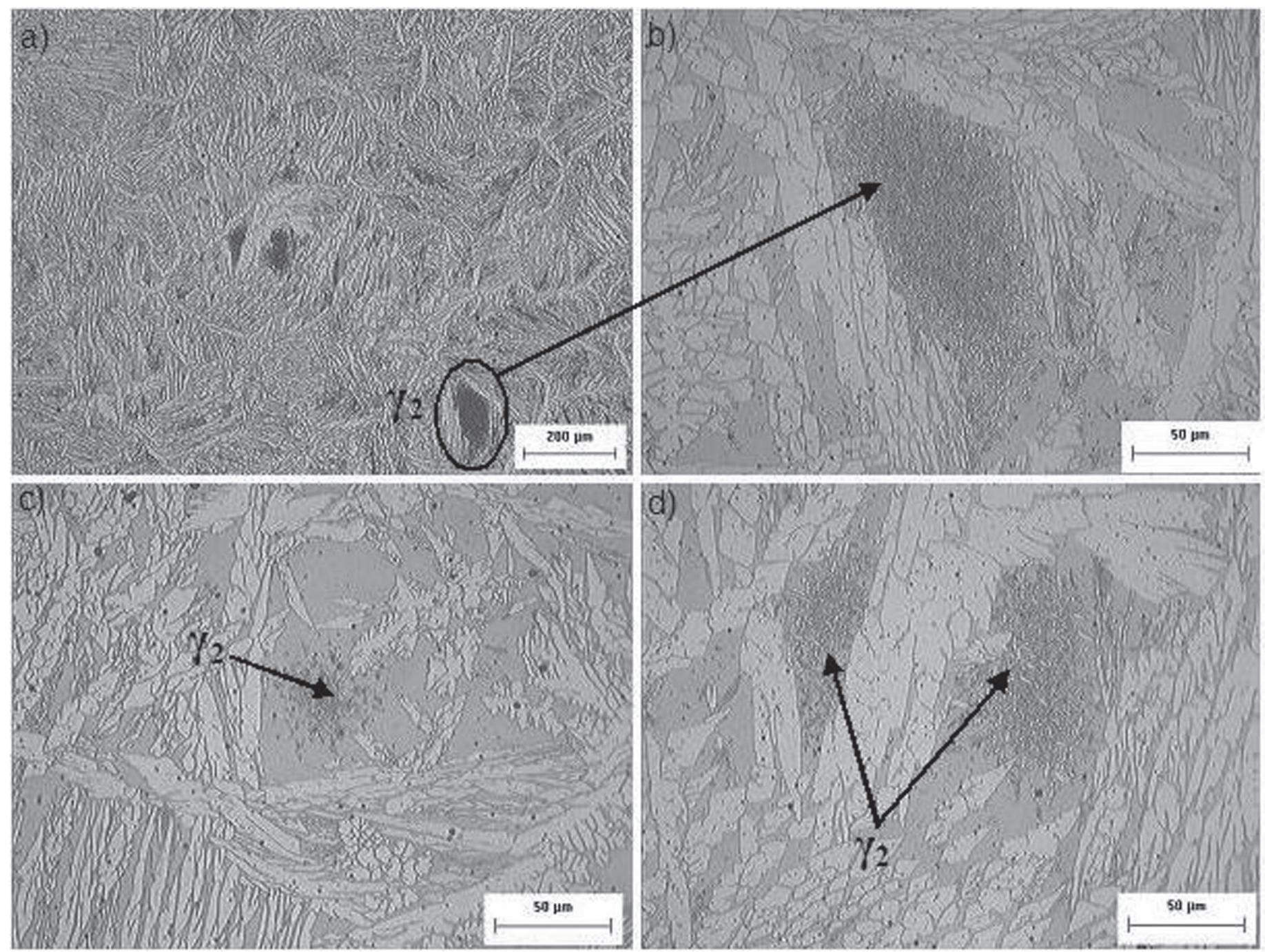

Figura 8. Microestrutura do metal de solda da condição C5P (E=24 kJ/cm, I = $135 \mathrm{~A}$ e Vs $=8,0 \mathrm{~cm} / \mathrm{min})$. Ataque $\operatorname{com} \mathrm{HNO}_{3}$. a) Aumento de 100x; b) até d) Aumento de 500x.

velocidade de soldagem $(8,0 \mathrm{~cm} / \mathrm{min})$, ou maior energia, apresentou uma maior presença de austenita secundária (Figura 8). Também foi verificado que na condição soldada com maior velocidade de soldagem $(13 \mathrm{~cm} / \mathrm{min})$ a quantidade de austenita Widmanstätten foi mais evidente devido possivelmente à maior taxa de resfriamento, o que pode ser confirmado pela formação de austenita com morfologia em forma de ripas (Figura 9).

Se a $\gamma_{2}$ intragranular tiver tempo para homogeneizar a sua composição química e a da matriz ao seu redor, o seu efeito prejudicial na resistência à corrosão do material pode ser evitado e, desta forma, será possível utilizar as suas vantagens para aumentar a fração total de $\gamma$ e reduzir o conteúdo de nitretos do material. Assim, são beneficiadas tanto a resistência à corrosão como a tenacidade. Muitas vezes ela é prejudicial no estágio inicial de precipitação, quando isto acontece em temperaturas suficientemente baixas, para que a redistribuição de elementos de liga seja dificultada. Ramirez verificou maior presença de austenita secundária para menores energias de soldagem, variando a corrente de soldagem para uma velocidade de soldagem constante [3].

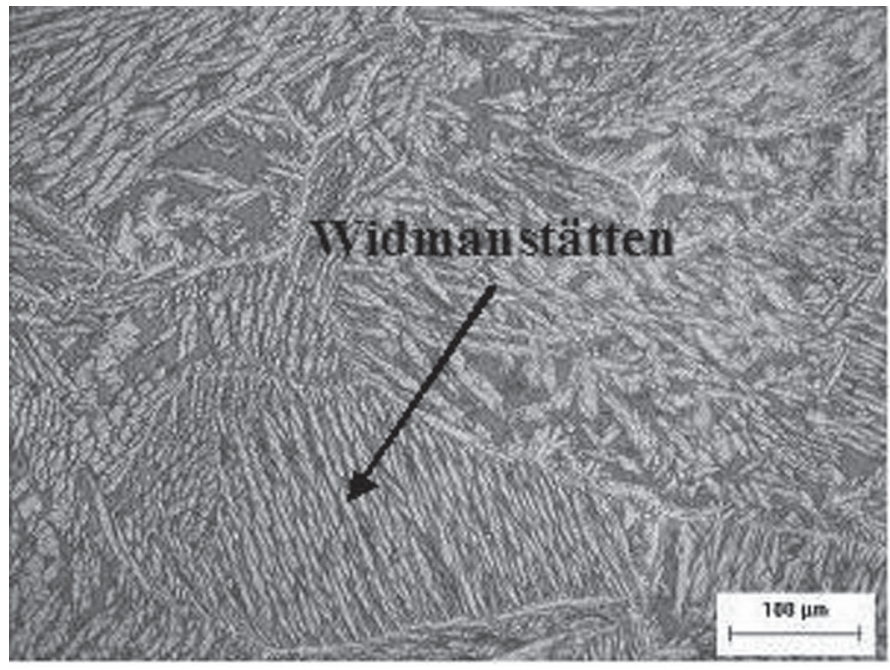

Figura 9. Microestrutura mostrando austenita em forma de ripas do metal de solda da condição $\mathrm{C} 4(\mathrm{E}=15 \mathrm{~kJ} / \mathrm{cm}, \mathrm{I}=135$ A e $\mathrm{Vs}=13 \mathrm{~cm} / \mathrm{min}$ ). Ataque com $\mathrm{HNO}_{3}$, aumento de 200x. 

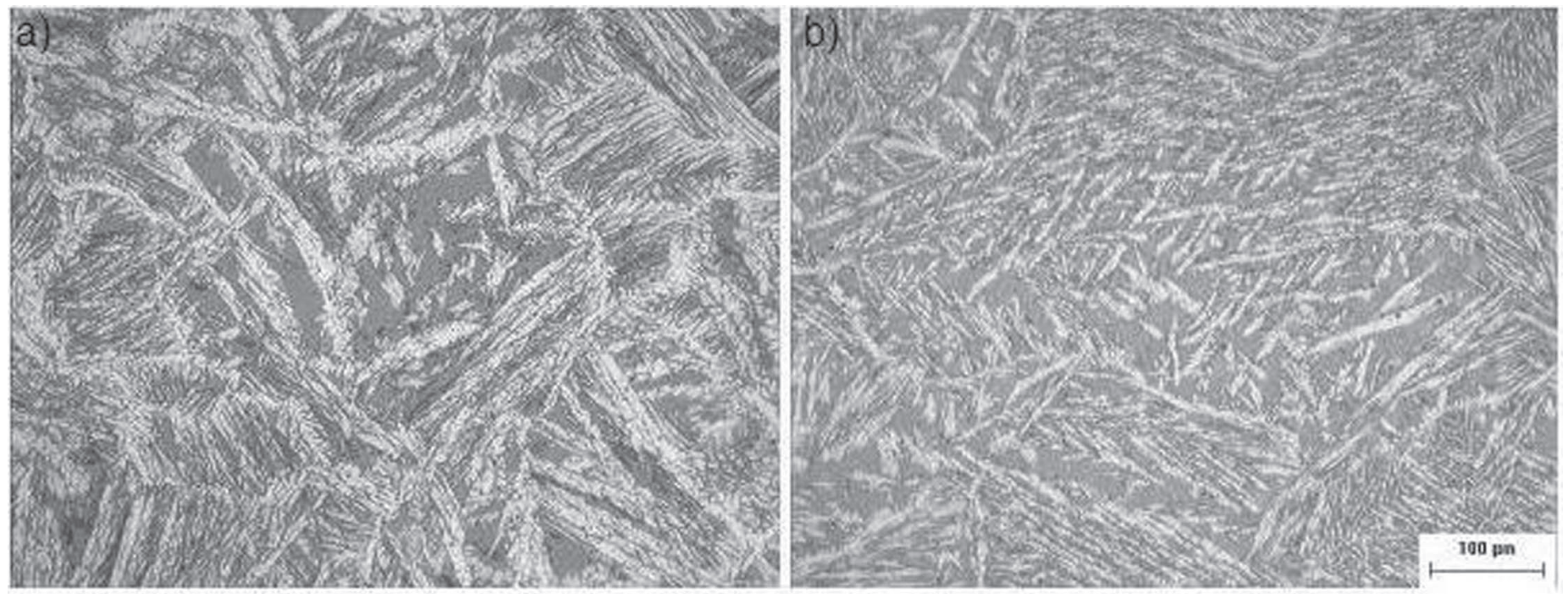

Figura 10. Microestrutura do metal de solda da condição C5 (E = 24 kJ/cm, I = 135 A e Vs = 8,0 cm/min). a) primeiro cordão soldado; b) último cordão soldado.
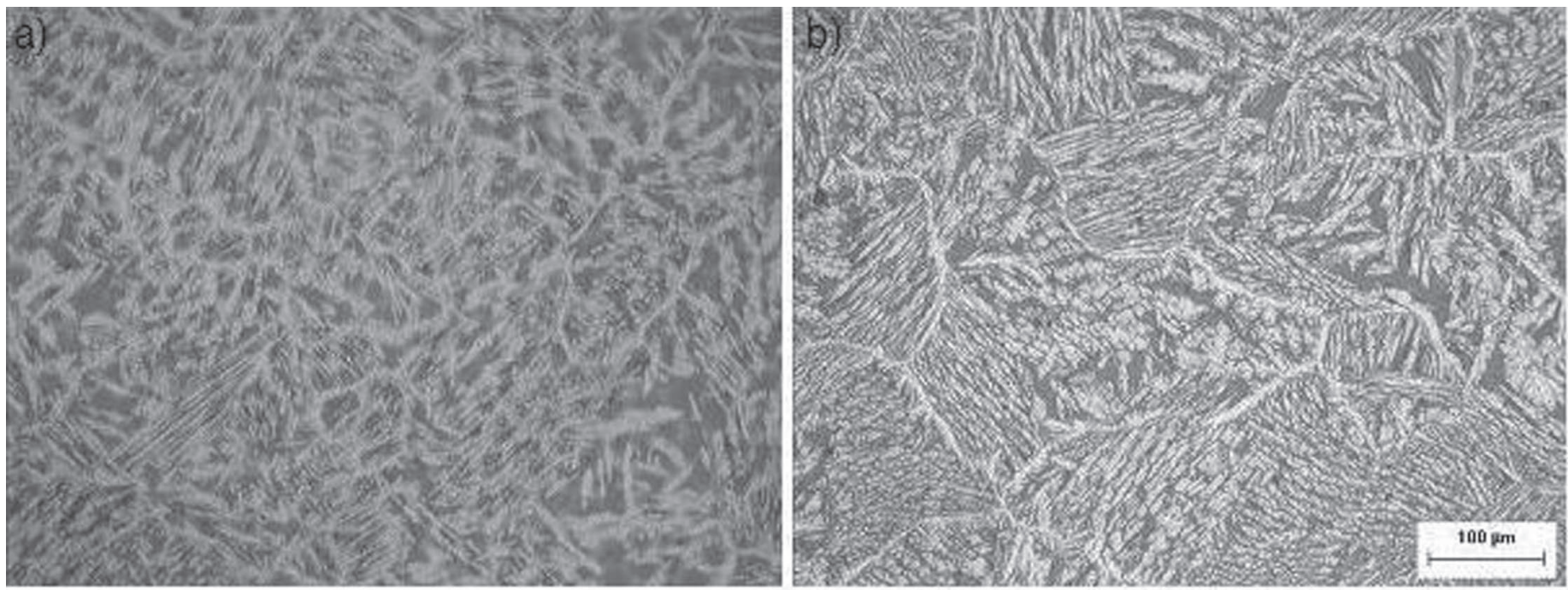

Figura 11. Microestrutura do metal de solda. A) condição $\mathrm{C} 1(\mathrm{E}=15 \mathrm{~kJ} / \mathrm{cm}) ; \mathrm{b})$ condição $\mathrm{C} 2(\mathrm{E}=24 \mathrm{~kJ} / \mathrm{cm})$.

a)

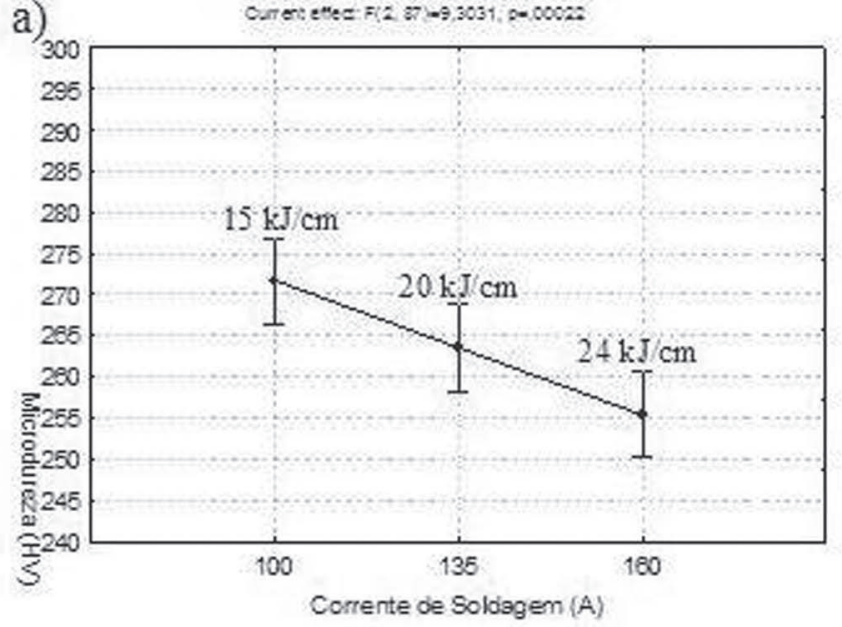

b)

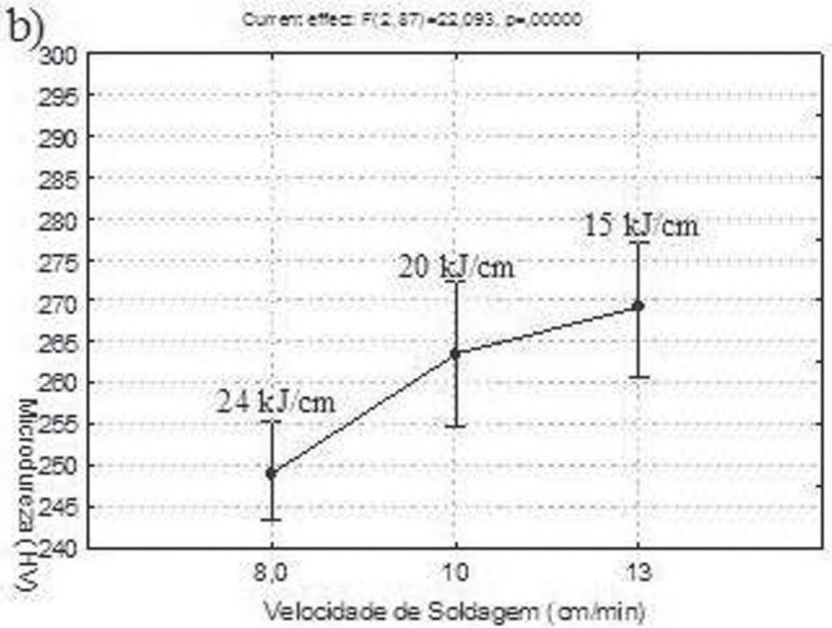

Figura 12. Microdureza no metal de solda de acordo com a variação da energia de soldagem. a) alteração da corrente de soldagem; b) alteração da velocidade de soldagem. 
No metal de solda de AID são distinguidos dois tipos de $\gamma_{2}$ [27]. Uma delas é formada nas interfaces $\alpha / \gamma$, na faixa de temperatura de 800 a $900^{\circ} \mathrm{C}$, e nada mais é do que o crescimento das partículas preexistentes de $\gamma$, porém com diferente composição química. Este tipo de $\gamma_{2}$ é melhor visualizado por Microscopia Eletrônica de Varredura (MEV). O outro tipo, que foi observado neste trabalho, é formado no interior da ferrita, na forma de finas partículas aciculares, na faixa de temperatura de 800 a $1000^{\circ} \mathrm{C}$. Segundo este autor, o processo de nucleação e crescimento desta austenita acicular mostra uma cinética de curva em "C", indicando que a transformação é controlada por difusão.

Acredita-se que a precipitação cooperativa do $\mathrm{Cr}_{2} \mathrm{~N}$ e da $\gamma_{2}$ tem uma relação direta com os baixos teores de $\mathrm{Cr}$ e $\mathrm{N}$ da $\gamma_{2}$, dado que o nitreto retira estes elementos da ferrita $\alpha$, que posteriormente transformar-se-á em $\gamma_{2}$. Desta maneira, a precipitação da $\gamma_{2}$ pode levar a uma diminuição na resistência à corrosão localizada [29].

Foram observados maiores grãos austeníticos nos primeiros cordões depositados em relação aos últimos (Figura 10). Este comportamento pode ser explicado pelo maior tempo de permanência às temperaturas elevadas, proporcionando maior crescimento de grãos austeníticos devido ao reaquecimento proporcionado pelos passes posteriores.

Em relação ao efeito da variação da energia (Figura 11), foi verificado que o aumento da energia de soldagem, tanto pelo acréscimo da corrente de soldagem, quanto pela redução da velocidade de soldagem, proporcionou a formação de microestrutura mais grosseira dos grãos ferríticos, porém esta análise deve ser feita com maior detalhamento por EBSD (Electron Backscatter Diffraction).

A presença a partir de $0,52 \%$ de fase sigma reduz a temperatura crítica de pites em aços inoxidáveis duplex a $40^{\circ} \mathrm{C}$, sendo de suma importância verificar a influência da formação de fase sigma na resistência à corrosão [30]. No entanto, em nenhuma condição soldada foi verificada a presença de fase sigma ou nitretos de cromo ao longo do metal de solda.

\subsection{Microdureza}

As análises dos resultados de microdureza não são simples, pois pode haver presença de fases complexas com propriedades diferentes, como: ferrita, austenita Widmanstätten, sigma, austenita intragranular, nitretos de cromo, chi, etc. Em soldagens de simples deposição, os resultados de microdureza não mostram grande variação em decorrência da variação da razão austenita/ ferrita, pois não há diferença significante na composição destas fases. Isto se explica porque os elementos substitucionais não tem tempo para se separarem durante a soldagem [31]. No entanto, em soldagens multipasse a avaliação é mais complexa devido ao efeito dos passes laterais, provocando aquecimento e reaquecimento e proporcionando maior formação de austenita, principalmente nos primeiros cordões, podendo contribuir para redução da microdureza nesta região. Em contrapartida, é importante salientar que nesta região há maior susceptibilidade para formação de fases intermetálicas que são fragilizantes, principalmente em condições soldadas com energia mais elevada, podendo ocasionar formação de fase chi, sigma etc.

Nas condições soldadas neste trabalho foram verificados níveis de microdureza similares entre passes e menores que 310 HV. Na Figura 12 são mostrados os níveis de microdureza devido à variação da energia, tanto pela alteração da corrente, quanto pela velocidade de soldagem.

O aumento da energia de soldagem pela alteração da corrente ou velocidade de soldagem acarretou na redução da microdureza no metal de solda. Este resultados podem estar relacionados com o maior tamanho de grão nas condições soldadas com maior nível de energia (Figura 11).

\section{Conclusões}

Com base nos resultados obtidos e apresentados no trabalho, foi possível concluir que:

- Os primeiros cordões depositados apresentaram menor quantidade de ferrita no metal de solda;

- A variação da energia de soldagem, na faixa recomendada pela literatura, não proporcionou diferenças significativas no percentual de ferrita no metal de solda;

- Nas condições em que houve a variação da energia pela alteração da corrente de soldagem, as de menores energias apresentaram maior quantidade de austenita secundária intragranular no metal de solda;

- A condição soldada com menor velocidade de soldagem $(\mathrm{V}$ $=8,0 \mathrm{~cm} / \mathrm{min}$ ) apresentou maior quantidade de austenita secundária intragranular no metal de solda;

- O aumento da energia de soldagem proporcionou formação de microestrutura mais grosseira dos grãos ferríticos;

- Todas as condições apresentaram níveis satisfatórios de microdureza, sendo que o aumento da energia de soldagem proporcionou redução dos níveis de microdureza.

- A variação da energia de soldagem não acarretou alteração significativa do balanço de fases (ferrita e austenita), de modo a não influenciar de maneira significativa na microdureza, porém a precipitação de fase secundária $\left(\gamma_{2}\right)$ pode acarretar em redução da resistência à corrosão e tenacidade.

\section{Agradecimentos}

Os autores agradecem ao Laboratório de Engenharia de Soldagem (ENGESOLDA) e ao Laboratório de Caracterização de Materiais (LACAM), ambos da Universidade Federal do Ceará pelo apoio laboratorial, além da FUNCAP, CAPES e $\mathrm{CNPq}$ pelo apoio financeiro.

\section{Referências Bibliográficas}

[1] LOPES, J. T. B. Influência da presença de fases frágeis e da temperatura nas propriedades de propagação de trinca por fadiga do aço inoxidável duplex UNS S31803. Tese (Doutorado)Departamento de Eng. de Materiais, Faculdade de Eng. Mecânica, U. Estadual de Campinas, Campinas, 2006.

[2] MARTINS, M.; CASTELETTI, L. C. Aços inoxidáveis duplex e super duplex-obtenção e caracterização. Revista 
Fundição e Serviços, ano 17, $\mathrm{n}^{\mathrm{0}}$ 169, 2007.

[3] LONDOÑO, A. J. R. Precipitação de fases intermetálicas e austenita secundária na ZAC de soldagens multipasse de aços inoxidáveis duplex. Tese (Doutorado) - Departamento de Eng. Metalúrgica, Escola Politécnica, U. de São Paulo, São Paulo, 2001.

[4] KAÇÃR, R.; ACARER, M. Microstructure-property relationship in explosively welded duplex stainless steel-steel. Materials Science and Engineering A363 290-296, 2003.

[5] NUNES, E. B. Propriedades mecânicas e caracterização microestrutural na soldagem do aço inoxidável duplex UNS S31803 (SAF 2205). Dissertação (Mestrado) - Departamento de Eng. Metalúrgica e de Materiais, Universidade Federal do Ceará, Fortaleza, 2009.

[6] PLATT, J. A. et al. Corrosion behavior of 2205 duplex stainless steel. American Journal of Orthodontics and Dentofacial Orthopedics, July 1997.

[7] MOURA, V. S. et al. Influence of microstructure on the corrosion resistance of the duplex stainless steel UNS S31803. Materials Characterization, 2007.

[8] GUNN, R. N. Duplex stainless steels-Microstructure properties and applications, Abington Publishing, Cambridge, UK, 1997.

[9] IACOVIELLO, F.; CASARI, F.; GIALANELLA, S. Effect of " $475{ }^{\circ} \mathrm{C}$ embrittlement" on duplex stainless steels localized corrosion resistance. Corrosion Science v. 47 p. 909-922, 2005.

[10] BERNHARDSSON, S. The corrosion resistance of duplex stainless steels. In: Conference Duplex Stainless Steels'91, Proceedings. France, 1991, p. 185-210, Beaune BourcogneFrance, 1991.

[11] FONTANA, M.G.; GREENE, N. D. Corrosion Engineering. New York, McGraw-Hill Book Company, 1967.

[12] SOLOMON, H. D.; DEVINE, T. M. A tale of two phases. In: Conference Duplex Stainless Steels'82,St. Louis-USA, 1982. Proceedings. Ohio, American Society of Metals, p. 693-756, 1983.

[13] MUTHUPANDI, V. et al. Effect of weld metal chemistry and heat input on the structure and properties of duplex stainless steel welds. Materials Science and Engineering A358. Janeiro, 2003.

[14] ECKENROD, J. J., PINNOW, K. E. Effects of chemical composition and thermal history on the properties of alloy 2205 duplex stainless steel. In: New Developments in Stainless Steel Technology. p. 77-87, 1984.

[15] BRANDI, S.D.; RAMÍREZ, A.J. Precipitation of intermatallic phases in the HAZ of multipass welding of duplex and superduplex stainless steels. In: International Conference Duplex Stainless Steels'97, Maastricht-The Netherlands. Proceedings. The Netherlands, KCI, 1997, p. 411-418, 1997.

[16] BERGLUND, G.; WILHELMSSON, P. Mater. Des. 10 p. 23-28, 1989.

[17] TECHNICAL SPECIFICATION. General Requirements in Using Duplex and Super Duplex Stainless Steel for Subsea Pipelines. CENPES-PETROBRAS.

[18] FEDELE, R. Corrosão intergranular em juntas soldadasparte III. revista soldagem \& inspeção - ano 6. $\mathrm{n}^{\circ} 5$.

[19] GIRALDO, C. P. S. Precipitação de fases intermetálicas na zona afetada pelo calor de temperatura baixa (ZACTB) na soldagem multipasse de aços inoxidáveis duplex. Dissertação (Mestrado) - Departamento de Eng. Metalúrgica, Escola Politécnica, U. de São Paulo. São Paulo, 2001.

[18] PALMER, T. A.; ELMER, J. W.; BABU, S. S. Observations of ferrite/austenite transformations in the heat affected zone of 2205 duplex stainless steel spot welds using time resolved X-ray diffraction. Materials Science and Engineering A 374 307-321, 2004.

[19] CHEN, T. H.; YANG, J. R. Microstructural characterization of simulated heat affected zone in a nitrogen-containing 2205 duplex stainless steel. Materials Science and Engineering A338 166-181, 2002.

[20] MUTHUPANDI, V.; et al. Effect of nickel and nitrogen addition on the microstructure and mechanical properties of power beam processed duplex stainless steel (UNS 31803) weld metals. Materials Letters 59 2305-2309, 2005.

[21] UREÑA, A.; OTERO, E.; UTRILLA, M. V.; MÚNEZ, C. J. Weldability of a 2205 duplex stainless steel using plasma arc welding. Journal of Materials Processing Technology $182 \mathrm{p}$. 624-631, 2007.

[22] LINDBLOM, B. E. S.; LUNDQVIST, B.; HANNERZ, N. E. Grain growth in HAZ of duplex stainless steels. Scandinavian Journal of Metallurgy, 20 p.305-315, 1991.

[23] MENEZES, J. W. A. et al. Crystallography of Widmanstätten Austenite in Duplex Stainless Steel Weld Metal. Editorial Manager(tm) for Science and Technology of Welding and Joining.

[24] CHEN, T. H.; YANG, J. R. Microstructural characterization of simulated heat affected zone in a nitrogen-containing 2205 duplex stainless steel. Materials Science and Engineering A338 166-181, 2002.

[25] NILSSON, J.O.; KARLSSON, L.; ANDERSSON, J.O. Formazione ed effetto dell'austenite secondaria nei cordoni di saldatura di acciai inossidabili duplex e superduplex. L' acciaio Inossidabile. n. 1, p. 18-22, 1994.

[26] ATAMERT, S.; KING, J.E. Intragranular nucleation of austenite. Z. Metallkde. v. 82, n. 3, p. 230- 239, 1991.

[27] NILSSON, J.O.; WILSON, A. Influence of isothermal phase transformations on toughness and pitting corrosion of super duplex stainless steel SAF 2507. Materials Science and Technology. v. 9, n. 7, p. 545-554, 1993.

[28] TAVARES, S. S. M. et al. Detecção de pequenos teores de fase sigma e Avaliação dos seus efeitos na resistência à corrosão do aço inoxidável duplex UNS S31803. Engevista, v.8, n.2, p. 77-82, 2006.

[29] TÁVARA, S. A. et al. Influence of nickel on the susceptibility to corrosion fatigue of duplex stainless steel welds. International Journal of Fatigue 23 619-626, 2001. 